\title{
Complete germline deletion of the STK11 gene in a family with Peutz-Jeghers syndrome
}

\author{
Nathalie Le Meur ${ }^{1,2}$, Cosette Martin ${ }^{1}$, Pascale Saugier-Veber ${ }^{1}$, Géraldine Joly ${ }^{1}$, Françoise \\ Lemoine $^{3}$, Hélène Moirot ${ }^{1}$, Annick Rossi ${ }^{1}$, Bruno Bachy ${ }^{4}$, Annick Cabot ${ }^{5}$, Pascal Joly ${ }^{6}$ \\ and Thierry Frébourg*,1,2
}

${ }^{1}$ Department of Genetics, CHU of Rouen, France; ${ }^{2}$ INSERM EMI 9906 - IFRMP, Faculty of Medicine, 76183 Rouen,
France; ${ }^{3}$ Department of Pathology, CHU of Rouen, France; ${ }^{4}$ Department of Pediatric Surgery, CHU of Rouen, France;
${ }^{5}$ Department of Ophtalmology, CHU of Rouen, France; ${ }^{6}$ Department of Dermatology, CHU of Rouen, France

Peutz-Jeghers syndrome (PJS, MIM175200) is an autosomal-dominant inherited disorder characterised by multiple gastrointestinal hamartomatous polyps, melanin spots of the oral mucosa and digits, and an increased risk for various neoplasms. The PJS results from germline alterations of the STK11/LKB1 tumour suppressor gene, located on 19p13.3, and encoding a serine/threonine kinase. The detection of STK11 germline mutations, in only $50-70 \%$ of PJS families, has suggested a genetic heterogeneity of the disease. We report the case of a family with typical features of PJS, including gastrointestinal hamartomatous, breast cancers and melanin spots of the oral mucosa. Quantitative multiplex PCR of short fluorescent fragments (QMPSF) of the $19 \mathrm{p} 13$ region allowed us to identify an approximately $250 \mathrm{~kb}$ heterozygous deletion removing entirely the STK11 locus. This report, which constitutes the first description of a complete germline deletion of STK11, shows that the presence of such large genomic deletions should be considered in PJS families without detectable point mutations of STK11.

European Journal of Human Genetics (2004) 12, 415-418. doi:10.1038/sj.ejhg.5201155

Published online 18 February 2004

Keywords: STK11; Peutz-Jeghers syndrome; deletion; QMPSF

\section{Introduction}

Peutz-Jeghers syndrome (PJS) is a rare autosomal-dominant disease associated with predisposition to benign and malignant tumours. The incidence has been estimated as one in 100000-200000 births. ${ }^{1-3}$ Patients present mucocutaneous pigmented macules, especially on the lips, buccal mucosa and digits, diffuse gastrointestinal hamartomatous polyposis and an increased risk of early-onset cancers, such as gastrointestinal carcinoma, breast cancer, genital tract tumours and pancreatic cancer. ${ }^{4}$ The gene

*Correspondence: Prof T Frebourg, INSERM EMI 9906 - IFRMP, Faculty of Medicine, 22 boulevard Gambetta, 76183 Rouen, France;

Tel: + 33232888182 ;

E-mail: Frebourg@chu-rouen.fr

Received 18 July 2003; revised 16 October 2003; accepted 30 October 2003 involved in PJS was mapped to chromosome 19p13.3 5 ,6 and was shown to be STK11/LKB1.,8 The STK11 gene contains 10 exons spanning $23 \mathrm{~kb}$, and encodes an ubiquitously expressed 433 amino-acid serine threoninekinase, which might be involved in G1 cell cycle arrest, ${ }^{9}$ p53-dependent apoptosis pathway, ${ }^{10}$ vascular endothelial growth factor regulation, ${ }^{11}$ and in the Wnt - -beta catenin signalling pathway. $^{12}$ Most of the STK11 mutations detected in PJS patients result in truncated proteins with incomplete catalytic domains without kinase activity. $^{7,8,13,14}$ PJS represents, therefore, the first cancer susceptibility syndrome resulting from germline inactivation of a kinase activity. The formation of hamartomatomas and cancers, in STK11 germline mutation carriers, results from the somatic inactivation of the wild-type allele, according to the Knudson model for tumour suppressor genes inactivation. ${ }^{5,15}$ Germline mutations of the STK11 gene 
can be detected in only $50-70 \%$ of PJS families ${ }^{7,16-18}$ and in $12-50 \%$ of individuals with sporadic PJS, ${ }^{16,19}$ which may reflect the involvement of other unidentified genes in PJS. Indeed, PJS families, not linked to chromosome $19 \mathrm{p} 13.3$, have already been reported. ${ }^{20,21}$ The alternative hypothesis, which might explain the absence of detectable STK11 germline mutations in some PJS families, is the existence of alterations, such as genomic rearrangements, which are missed by conventional screening methods.

We report here, for the first time, the detection of a complete genomic deletion of the STK11 locus in a family with PJS.

\section{Patients and methods Patients}

The proband, born in 1987, was a male from nonconsanguineous parents and the youngest of three siblings. He was initially referred to our department of genetics for learning disabilities and scoliosis. Examination revealed 'Café-au-lait' spots and led to the diagnosis of neurofibromatosis type 1 , which was confirmed by the presence of Lisch nodules. At the age of 13 years, he presented an occlusive syndrome with rectal prolapse in relation with a large $(5 \times 4 \mathrm{~cm})$ sigmoid polyp. The existence of a lentiginosis of the inferior lip led us to suspect a PJS, which was confirmed by pathological examination of the polyp. The father presented 'café au lait' spots and a thoracic neurofibroma, which was consistent with the paternal origin of neurofibromatosis type 1 . The mother of the index case had developed, (i) at the age of 43 years, recurrent hamartomatous polyps and a colorectal cancer revealed by bleeding, (ii) at the age of 44 years, a rightbreast carcinoma and, (iii) at the age of 45 years, a leftbreast carcinoma. The maternal uncle, presented hamartomatous polyps of the colon and colorectal cancer at the age of 43 years. Re-examination of the polyps developed in the mother and the maternal uncle, after the diagnosis of PJS in the index case, confirmed that these polyps were consistent with the diagnosis of PJS. Therefore, the proband had simultaneously an NF1 from paternal origin and a PJS from maternal origin.

\section{Microsatellite analysis}

The centromeric and telomeric microsatellite markers D19S886 and D19S883, respectively, located $180 \mathrm{~kb}$ upstream and $234 \mathrm{~kb}$ downstream of STK11, were PCR amplified from genomic DNA using dye-labelled primers and analysed on an automated sequencer (Applied Biosystems) using the Gene scanner Model 672 Fluorescent Fragment Analyzer (Applied Biosystems).

Fluorescence. in situ hybridization (FISH) analysis The RP11-75H6 BAC, obtained from the University of Bari, Italy (http://www.biologia.uniba.it/rmc), was labelled using the Nick translation Reagent Kit (Vysis) and fluorescein-labelled dUTPs (Vysis). Metaphase chromosome spreads and probe were denatured at $72^{\circ} \mathrm{C}$ for $1 \mathrm{~min}$, then hybridized at $37^{\circ} \mathrm{C}$ overnight. Chromosome counterstaining was performed with $0.1 \mu \mathrm{g} / \mathrm{ml} \mathrm{4}$, 6-diamidino-2-phenylindole (DAPI) in antifade solution. Slides were visualized on a Nikon-Microphot-FXA microscope and the images were captured using the ISIS digital FISH imaging system (Metasystem).

\section{Quantitative multiplex PCR of short fluorescent fragments (QMPSF)}

Short exonic fragments, corresponding to the 10 exons of STK11 and to the exon 13 of $H M B S / P B G D$ located on chromosome 11, used as control, were simultaneously amplified in a first QMPSF. To examine the extent of the deletion, we designed a second QMPSF including exon 1 of $W D R 18$, exon 5 of $M I D N$, exon 18 of DAZAP1 and exon 18 of MLH1, used as control. Sequences of primers are indicated in Table 1.

\section{Results}

The remarkable association of NF1 and PJS features in the same patient led us initially to test the involvement of the STK11 gene within this family. Therefore, we analysed first the segregation of the D19S886 and D19S883 microsatellite markers, surrounding the STK11 locus, in the index case, the mother and maternal uncle whose clinical presentation was consistent with PJS. Unexpectedly, this analysis showed an absence of maternal contribution of D19S886 in the proband, suggesting therefore a 19p13.3 heterozygous deletion inherited from his affected mother (data not shown). Chromosome analysis performed on cultured peripheral blood lymphocytes from the proband, using standard R-banding, revealed no alteration at the 400 band level. FISH analysis, performed with a genomic probe prepared from the RP11-75H6 clone, revealed an asymmetric signal between the two chromosomes 19, which indicated that this BAC overlapped the deleted region (data not shown). In order to confirm the heterozygous deletion of STK11 and to map precisely the deletion, we used QMPSF, a method based on simultaneous amplification of multiple short sequences under quantitative conditions. ${ }^{22}$ QMPSF, performed in the proband, his mother and maternal uncle, confirmed the deletion and revealed that this deletion removed all the exons of STK11 (Figure 1a). In contrast, the telomeric WDR18, and centromeric DAZAP1 and MIDN genes were not deleted (Figure 1b).

\section{Discussion}

We document here for the first time, in a PJS family, using microsatellite, FISH and QMPSF analysis, a complete heterozygous deletion of the STK11 locus. Results from 
Table 1 Primers used for the QMPSF ${ }^{a}$

\begin{tabular}{|c|c|c|c|c|}
\hline Gene & Exon & Sense primer ${ }^{b}$ & Antisense primer $^{c}$ & Size of the amplicon ${ }^{d}$ \\
\hline STK11 & 1 & 5' CGAGCTGATGTCGGTGGGT 3' & 5' ACAGCGTCTCCGAGTCCAG 3' & 193 \\
\hline STK11 & 2 & 5' ATCATCCTGACGTTGGGTCG 3' & $5^{\prime}$ GGAGACGGGAAGAGGAGCAG $3^{\prime}$ & 248 \\
\hline STK11 & 3 & 5' CССТССАGAGССССТTTT 3' & 5' CACGCTGTCCAGCATTTCC $3^{\prime}$ & 161 \\
\hline STK11 & $4-5$ & $5^{\prime}$ CGGTGGCACCCTCAAAAT $3^{\prime}$ & 5' GACCCCAGCCGACCAGAT 3' & 267 \\
\hline STK11 & 6 & 5' TGGGTCCAGAGGACACTCCC $3^{\prime}$ & 5' СССТTCССGАTGTTCTCAAA 3' & 291 \\
\hline STK11 & 7 & 5' CCGGCTTCTCСТCAGGGAT 3' & $5^{\prime}$ TCTAGCGCCCGCTCAACC $3^{\prime}$ & 174 \\
\hline STK11 & 8 & 5' CTGCTTCTGGGCGTTTGC $3^{\prime}$ & 5' ACCGTGAAGTCCTGAGTGTAGAT 3' & 220 \\
\hline STK11 & 9 & 5' СТTGССGTСТСССТСССА $3^{\prime}$ & 5' TCCGCCCTGGATTTGGTG $3^{\prime}$ & 151 \\
\hline STK11 & 10 & 5' GAGTCCGGTAGCCCCATGA 3' & $5^{\prime}$ TGGTCGGCACAGAAGCATG $3^{\prime}$ & 237 \\
\hline WDR18 & 1 & 5' ATGTGGAGCTGCATCGTGT 3' & 5' CCCAGGCGCTGATGTAATT 3' & 169 \\
\hline MIDN & 5 & $5^{\prime}$ CCGTTCGCCACTGACACT $3^{\prime}$ & 5' CACGGGGGAGGCTATGCT3' & 181 \\
\hline DAZAP1 & 11 & $5^{\prime}$ TTACGGGCAGGACTTGAGTGG $3^{\prime}$ & 5' GTCACGAGTTCACAAGTTTGG $3^{\prime}$ & 253 \\
\hline MLH1 & 18 & 5' GTAGTCTGTGATCTCCGTTT $3^{\prime}$ & 5' ATGTATGAGGTCCTGTCCTA $3^{\prime}$ & 266 \\
\hline HMBS & 13 & $5^{\prime}$ TAGACGGCTCAGATAGCATACAAG $3^{\prime}$ & $5^{\prime}$ ATGCCTACCAACTGTGGGTCA $3^{\prime}$ & 208 \\
\hline
\end{tabular}

${ }^{a}$ Sequences and location of primers were based on the chromosomes 19 and 2 working draft sequences (Build 33).

${ }^{\mathrm{b}}$ Carry the 5' extension: CGTTAGATAG and are 5'(6-Fam) end labelled.

${ }^{c}$ Carry the $5^{\prime}$ extension: GATAGGGTTA.

din bp.

Note: PCR were performed in a final volume of $25 \mu$ l containing $100 \mathrm{ng}$ of genomic DNA, $0.15-1 \mu \mathrm{M}$ of each primer, $200 \mu \mathrm{M} \mathrm{dNTPs}, 1.5 \mathrm{mM} \mathrm{MgCl}$, $10 \%$ of DMSO and $1 \mathrm{U}$ of Taq DNA polymerase (Abgene). The PCR consisted of $22-25$ cycles of $94^{\circ} \mathrm{C}$ for $15 \mathrm{~s}, 50^{\circ} \mathrm{C}$ for $15 \mathrm{~s}$ and $72^{\circ} \mathrm{C}$ for $15 \mathrm{~s}$, preceded by an initial denaturation step of $5 \mathrm{~min}$ at $94^{\circ} \mathrm{C}$ and followed by a final extension of $5 \mathrm{~min}$ at $72^{\circ} \mathrm{C}$. PCR products $(1 \mu \mathrm{l})$ were resuspended in a mix containing $1.25 \mu \mathrm{l}$ of deionised formamide, $0.5 \mu \mathrm{l}$ of GeneScan-500 Rox (PE Applied Biosystems, Foster City, CA, USA) and $1 \mu \mathrm{l}$ of loading buffer. After denaturation for $3 \mathrm{~min}$ at $95^{\circ} \mathrm{C}, 2 \mu \mathrm{l}$ of each sample was loaded onto a $6 \%$ denaturing polyacrylamide gel (Sequagel). Electrophoresis was performed for $3 \mathrm{~h}$ on an Applied Biosystems model 377 automated sequencer (PE Applied Biosystems, Foster City, CA, USA). Data were analysed using the Gene Scanner Model 672 Fluorescent Analyser (PE Applied Biosystems, Foster City, CA, USA).

the microsatellite markers and QMPSF analysis allowed us to locate the telomeric breakpoint between WDR18 exon 1 and D19S886 and the centromeric breakpoint between STK11 exon 10 and MIDN exon 5 (Figure 2), and to estimate the size of this 19p13.3 deletion between 220 and $250 \mathrm{~kb}$. According to the chromosome $19 \mathrm{draft}$ sequence (http://www.ncbi.nlm.nih.gov/LocusLink), this deletion
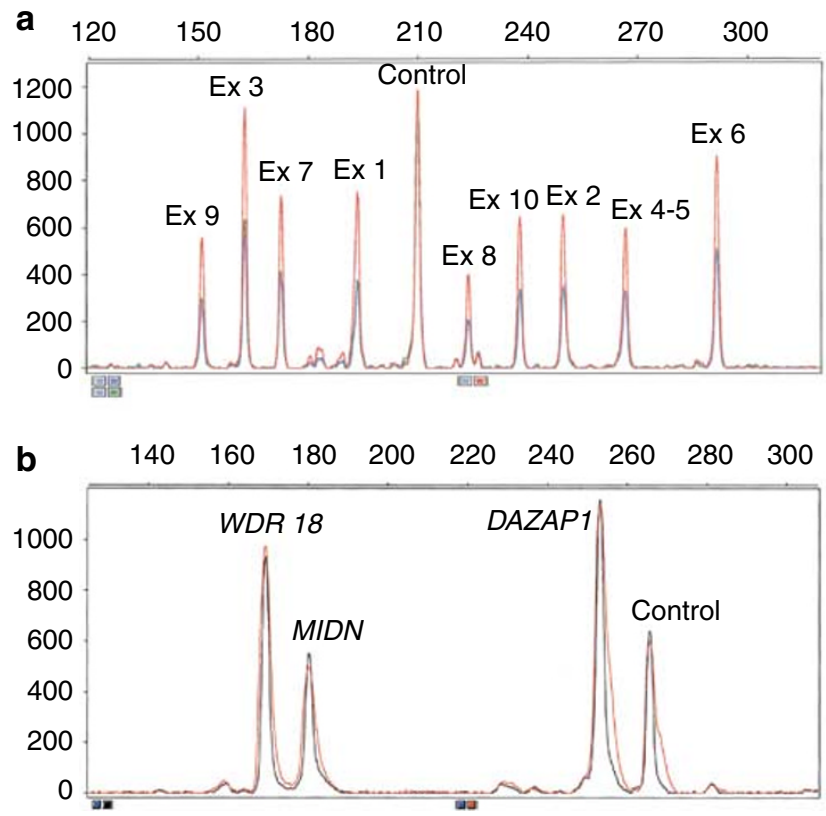

also removed, in addition to STK11, the GPX4, POLR2E, $H A-1, C N N 2$ and $A B C A 7$ genes encoding, respectively, the glutathion peroxydase-4, the subunit E of DNA-dependant polymerase II, a minor histocompatibility antigen, the calponin 2 and an ATP-binding cassette protein (Figure 2).

To date, approximately 100 different mutations of STK11 have been described in PJS patients (Human Gene Mutation Database: http://archive.uwcm.ac.uk/uwcm/mg/ hgmd0.html). Most mutations are nucleotide substitutions and small insertions or deletions. At the present time, four partial genomic rearrangements of STK11 have been detected: a deletion of the end of intron 6 and the majority

Figure 1 Detection and characterization of the boundaries of the 19p13 deletion using QMPSF. The $Y$-axis displays fluorescence in arbitrary units, and the $X$-axis indicates the size in bp. (a) Deletion of exons 1-10 of STK11. The electropherograms of the index case (in blue) and of the affected mother (in green) were superimposed to that of the unaffected father (in red), used as control, by adjusting to the same level the peaks obtained for the control amplicon (HMBS exon 13). Heterozygous deletion of the STK11 exons is visualised by a $50 \%$ reduction of the corresponding peaks height. The same profile was obtained for the affected uncle. (b) Absence of deletion of the telomeric WDR18 and, of the centromeric MIDN and $D A Z A P 1$ genes. The electropherogram of the index case (in black) was superimposed to that of the unaffected father (in red) by adjusting to the same level the peaks obtained for the control amplicon (MLH1 exon 18). 


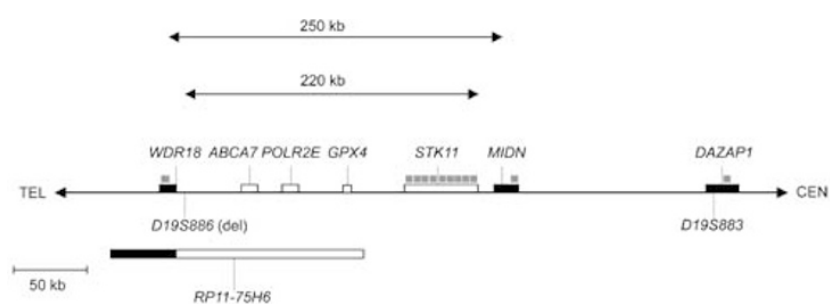

Figure 2 Schematic representation of the 19p13.3 deletion removing the STK11 locus. CEN and TEL indicate the centromeric and telomeric sides. Genes are indicated above the line and microsatellite markers and the BAC clone used for the FISH analysis below. Grey boxes show the positions of QMPSF amplicons. The deleted regions are designed by white boxes and nondeleted regions by black boxes. Del: deleted. The minimal and maximal estimated sizes of the deletion are indicated by arrows.

of exon $7,{ }^{13}$ a complex rearrangement including a deletion of exons 4-5 and an inversion of exons 6-7 detected by long-distance PCR, ${ }^{8}$ a deletion of exons $2-7$ and a part of exon $8^{23}$ revealed by Protein Truncation Test and a $2 \mathrm{~kb}$ deletion detected by Southern blot. ${ }^{16}$ Our study shows that complete heterozygous rearrangements of STK11 also occur in PJS. PJS families linked to $19 \mathrm{p} 13$ and without detectable mutation of STK11 have already been described. ${ }^{7,16}$ The presence of such genomic rearrangements, which are missed by conventional screening methods, based on PCR amplification of each exon, should be therefore considered in PJS families without detectable alteration. The QMPSF method, which can detect heterozygous deletions affecting either a single or several exon(s), should allow to estimate the relative contribution of STK11 deletions in the aetiology of PJS.

\section{Acknowledgements}

We are grateful to Mario Tosi for a critical review of the manuscript. This work was supported by l'Association pour la Recherche sur le Cancer.

\section{References}

1 Linder NM, Greene MH: The concise hanbook of family cancer syndromes. J Natl Cancer Inst 1998; 90: 1039-1071.

2 Järvinen HJ: Genetic testing for polyposis: practical and ethical aspects. Gut 2003; 52: 19-22.

3 Grady WM: Genetic testing for high-risk colon cancer patients. Gastroenterology 2003; 124: 1574-1594.

4 McGarrity TJ, Kulin HE, Zaino RJ: Peutz-Jeghers syndrome. Am J Gastroenterol 2000; 95: 596-604.

5 Hemminki A, Tomlinson I, Markie D et al: Localization of a susceptibility locus for Peutz-Jeghers syndrome to $19 \mathrm{p}$ using comparative genomic hybridization and targeted linkage analysis. Nat Genet 1997; 15: 87-90.

6 Amos CI, Bali D, Thiel TJ et al: Fine mapping of a genetic locus for Peutz-Jeghers syndrome on chromosome 19p. Cancer Res 1997; 57: $3653-3656$

7 Hemminki A, Markie D, Tomlinson I et al: A serine/threonine kinase gene defective in Peutz-Jeghers syndrome. Nature 1998; 391: $184-187$.

8 Jenne DE, Reimann H, Nezu J et al: Peutz-Jeghers syndrome is caused by mutations in a novel serine threonine kinase. Nat Genet 1998; 18: 38-43.

9 Tiainen M, Ylikorkala A, Makela TP: Growth suppression by Lkb1 is mediated by a G(1) cell cycle arrest. Proc Natl Acad Sci USA 1999; 96: 9248-9251.

10 Karuman P, Gozani O, Odze RD et al: The Peutz-Jegher gene product LKB1 is a mediator of p53-dependent cell death. Mol Cell 2001; 7: 1307-1319.

11 Ylikorkala A, Rossi DJ, Korsisaari N et al: Vascular abnormalities and deregulation of VEGF in Lkb1-deficient mice. Science 2001; 293: $1323-1326$.

12 Spicer J, Rayter S, Young N, Elliott R, Ashworth A, Smith D: Regulation of the Wnt signalling component PAR1A by the Peutz-Jeghers syndrome kinase LKB1. Oncogene 2003; 22: 47524756.

13 Mehenni H, Gehrig C, Nezu J et al: Loss of LKB1 kinase activity in Peutz-Jeghers syndrome, and evidence for allelic and locus heterogeneity. Am J Hum Genet 1998; 63: 1641-1650.

14 Nakagawa H, Koyama K, Miyoshi Y et al: Nine novel germline mutations of STK11 in ten families with Peutz-Jeghers syndrome. Hum Genet 1998; 103: 168-172.

15 Miyaki M, Iijima T, Hosono K et al: Somatic mutations of LKB1 and beta-catenin genes in gastrointestinal polyps from patients with Peutz-Jeghers syndrome. Cancer Res 2000; 60: 6311-6313.

16 Ylikorkala A, Avizienyte E, Tomlinson IP et al: Mutations and impaired function of LKB1 in familial and non-familial PeutzJeghers syndrome and a sporadic testicular cancer. Hum Mol Genet 1999; 8: $45-51$.

17 Olschwang S, Boisson C, Thomas G: Peutz-Jeghers families unlinked to STK11/LKB1 gene mutations are highly predisposed to primitive biliary adenocarcinoma. J Med Genet 2001; 38: 356360.

18 Lim W, Hearle N, Shah B et al: Further observations on LKB1/ STK11 status and cancer risk in Peutz-Jeghers syndrome. $\mathrm{Br} \mathrm{J}$ Cancer 2003; 89: 308-313.

19 Scott RJ, Crooks R, Meldrum CJ et al: Mutation analysis of the STK11/LKB1 gene and clinical characteristics of an Australian series of Peutz-Jeghers syndrome patients. Clin Genet 2002; 62: $282-287$.

20 Mehenni H, Blouin JL, Radhakrishna U et al: Peutz-Jeghers syndrome: confirmation of linkage to chromosome 19p13.3 and identification of a potential second locus, on 19q13.4. Am J Hum Genet 1997; 61: 1327-1334.

21 Olschwang S, Markie D, Seal S et al: Peutz-Jeghers disease: most, but not all, families are compatible with linkage to $19 \mathrm{p} 13.3$. J Med Genet 1998; 35: 42-44.

22 Charbonnier F, Raux G, Wang Q et al: Detection of exon deletions and duplications of the mismatch repair genes in hereditary nonpolyposis colorectal cancer families using multiplex polymerase chain reaction of short fluorescent fragments. Cancer Res 2000; 60: 2760-2763.

23 Jiang CY, Esufali S, Berk T et al: STK11/LKB1 germline mutations are not identified in most Peutz-Jeghers syndrome patients. Clin Genet 1999; 56: 136-141. 